\title{
Principals' Attitudes Towards the Suitability of Irish Language Immersion Education for Children with Dyslexia
}

\author{
Rachael Patton \& Elizabeth Mathews \\ Gaelscoil Ros Eo \& DCU School of Inclusive Education \\ rachael@gaelscoilroseo.com
}

\begin{abstract}
This study explores principals' attitudes towards the suitability of language immersion education (LIE) enrolment for children with dyslexia in Ireland. It also aims to examine the challenges faced by those in LIE settings working to include children with special educational needs (SEN), specifically dyslexia, in their schools. Participants include primary school principals working in Irish LIE settings across Ireland. The study follows a mixed methods approach including a focus group interview and a self-completion online questionnaire. Results indicate that principals believe that LIE enrolment is suitable for children with dyslexia and that these children can benefit from being placed in such a learning environment. However, the Irish immersion system faces considerable challenges in its aims to support children with dyslexia, namely the lack of an appropriate assessment system, the lack of sufficient research and training and negative attitudes held towards the Irish language.
\end{abstract}

Keywords: immersion education; dyslexia, principal, inclusion, special education

\section{Introduction}

The majority of research carried out on language immersion education (LIE) has focused on the typically developing child while the majority of research carried out on children with special educational needs (SEN) has focused on the monolingual child (Bruck, 1978; Cline, 2000; Ware, 2011; Ware, Lye \& Kyffin, 2015). Indeed, teachers often regard the inclusion of children with SEN as one significant challenge and separately, bilingual immersion education as another, neither of which they feel sufficiently trained in (Barrett, 2016; Ware, 2011). Subsequently, there have been calls for further research on LIE for 
children with SEN both in Ireland (Barrett, 2016; COGG, 2010; Ní Chiaruáin, 2009) and internationally in Canada (Cobb, 2014), Australia (de Courcy, 2005) and the UK (Ware, Lye and Kyffin, 2015). This considerable gap in the research has resulted in some educators and clinical professionals assuming LIE is unsuitable for children with SEN (Cummins, 1983; Flynn et al., 2019) or in failure to provide supports for children with SEN within LIE programmes (Cobb, 2014). Furthermore, parents may resort to taking advice based on speculation (Ware et al., 2011; Flynn et al., 2019) resulting in migration out of LIE programmes. This article examines the issue of LIE for children with dyslexia in the Irish context. Specifically, it examines principals' attitudes towards the suitability of LIE for pupils with dyslexia.

\subsection{Language Immersion Education in Ireland}

Recent census reports that while approximately $40 \%$ of the Irish population reported that they are able to speak Irish, a much smaller number (less than $2 \%$ ) use Irish on a daily basis (Central Statistics Office, 2017). A considerable proportion of the remainder (13\%) speak Irish within the education system, often with a lack of motivation to do so (Hickey $\&$ Stenson, 2016), highlighting the role of the education system in preserving the use of Irish nationally. Indeed, there are a number of ways in which the Irish language is promoted in the education system including an extensive and varied number of approaches and resources, the recognition of the benefits of learning a second language (Hickey, 2001) and the provision of Irish LIE programmes. Ó’Murchú (2001) highlights that there are two components of this system. The first component is the system of Irish language medium schools within the regions of the country where many (though not all) of the pupils enrolled will use Irish as their first language at home - hereafter referred to as Scoileanna Gaeltachta (translating as schools in the Irish speaking regions). These regions are known as the Gaeltacht and largely comprise rural coastal areas along the West of Ireland. The second component is the system of Irish language medium schools outside the Gaeltacht where there is much variation in the fluency and use of the Irish language among pupils and their families - hereafter referred to as Gaelscoileanna (translating as Irish medium schools). It is not unusual for children in these settings to come from homes where no Irish is spoken at all. In the 2017/2018 academic year, there were 102 primary level Scoileanna Gaeltachta teaching all subjects through Irish and a further 146 Gaelscoileanna teaching all subjects through Irish (Department of Education and Skills 2017). This comprises a little under $8 \%$ of the total mainstream primary 
education system. LIE within Gaelscoileanna in particular is becoming increasingly popular, with reports of oversubscription (Darmody \& Daly, 2015). However, LIE settings are often not realised for children with SEN, a problem characteristic of immersion education in other jurisdictions (Cobb, 2014).

Both Gaelscoileanna and Scoileanna Gaeltachta were included in this study, both considered as LIE settings but very different in terms of the linguistic context of the communities within which they are located. Scoileanna Gaeltachta are located in Irish speaking communities where Irish is often, but not always, the language spoken at home. Gaelscoileanna differ in that they are located in English speaking areas and the children attending them often have English as a first language. Enrolment in Gaelscoileanna often indicates a commitment to LIE on behalf of parents who have chosen it above alternative school options in the locality. The same is not necessarily the case for Scoileanna Gaeltachta where the LIE nature of the school is by virtue of its geographical location within an Irish speaking area.

\subsection{Pupils with SEN and Language Immersion Education}

While there is a dearth of research regarding the suitability of LIE for children with dyslexia in Ireland, there is international research available regarding the inclusion of pupils with SEN in LIE programmes more broadly. Some of this research shows that there is no disadvantage to LIE for pupils with SEN. For example, Bruck (1978) carried out a longitudinal project over six years monitoring the progress of pupils with and without SEN in both French LIE programmes and monolingual English medium programmes in Canada. Progress was monitored in three areas including the pupils' first language English (L1) and their second language, French (L2), cognitive development and general success at school. The research found that by the end of grade one (senior infant equivalent in Ireland) children with SEN in the LIE programme were not experiencing any greater difficulty than their peers with SEN in the monolingual programme. While all children in the LIE programme experienced some difficulty during grade two (the time when English is introduced), language proficiency had improved by grade three.

Similarly, in the United States a study comparing standardised test results of children with SEN in Spanish LIE programmes and English-medium settings found that those with SEN in LIE programmes succeeded academically on par with their monolingual peers 
with SEN (Myers, 2011). Subsequently, it would appear that for some categories of pupils with SEN, enrolment in LIE programmes leads to no greater difficulties than they would in a monolingual school (Bruck, 1978; Myers, 2011). Bruck (1978) acknowledges that while children with SEN have disabilities that cannot be 'solved' by LIE, they can benefit from a bilingual education in that they not only develop cognitive, academic and linguistic skills at a rate similar to that of their peers with SEN in monolingual settings, but also acquire a second language.

However, Gaffney (1999), identified a subgroup of 'at-risk' learners that include children who have not typically matured linguistically or cognitively and may fail to succeed under the added pressure of immersion education. One such 'at-risk' subgroup may be those with reading impairments. Genesee and Jared (2008) reviewed four research studies examining children in LIE programmes with poor reading ability and children at risk of reading impairment. Combining the findings of the four studies Genesee and Jared reported that children who were at risk of reading difficulty in their first language were also at risk in their second language. Likewise, children who performed well in their first language also performed well in their second language therefore drawing attention to a correlation between ability across languages. Genesee and Jared (2008) also found that the fundamentals of the early stages of reading in a bilingual programme are the same as those in a monolingual programme. Moreover, they reported children with SEN in French immersion programmes in Canada scored higher in reading ability than their peers in English medium schools highlighting LIE not only as suitable but beneficial (Genesee \& Jared 2008). The current study sought to examine whether or not children with dyslexia are perceived to be such an 'at-risk' group in the Irish LIE context.

While acknowledging the absence of a globally accepted definition for dyslexia, Reid (2016) has defined it as followed:

"A processing difference, often characterised by difficulties in literacy acquisition affecting reading, writing and spelling. It can also have an impact on cognitive processes such as memory, speed of processing, time management, coordination and automaticity. There may be visual and/or phonological challenges and there are usually some discrepancies in education performances." (p. 5) 
Dyslexia is a neurodevelopmental and neurobiological disorder (Peterson and Pennington 2012), characterised by difficulties in spelling, decoding and fluency in word recognition. A deficit in phonological awareness has been identified as a difficulty related to dyslexia across the literature (International Dyslexia Association, 2016; Joshi, Padakannaya \& Nishanimath, 2010; Peterson \& Pennington, 2012; Reid, 2016). The International Dyslexia Association (2016) explains that poor comprehension skills are often recognisable in students with dyslexia. It is best understood as a continuum of need (Reid, 2004; McPhillips, Bell and Doveston, 2009). When considering the profile of children with dyslexia one should also consider their strengths as researched by Everatt, Weeks and Brooks (2007). Such strengths include the use of compensatory methods, the application of context priming strategies, general language and visual-spatial ability as well as non-verbal and spatial memory skills.

Miller-Guron and Lundberg (2000), Joshi et al. (2010) and Wydell and Butterworth (1999) all investigate bilingual children with dyslexia, however, none of them suggest bilingualism or immersion education as unsuitable for children with dyslexia. On the contrary Miller-Guron and Lundberg (2000) suggest that second language learning may be used as a strategy to allow children with dyslexia to better access literacy in the case where the second language may have a more transparent orthography.

While English and Irish share similar alphabets the orthographies of the two languages differ significantly. Irish orthography is quite consistent (Parsons \& Lyddy, 2015) while English orthography is deeper (Hickey, 2007). Joshi et al. (2010) hypothesise that the orthographic depth of a language or the relationship between a language'orthography and phonology can determine the level of difficulty in literacy acquisition. Similarly, Parsons and Lyddy (2009) suggest the more regular orthography of Irish may reinforce the sounding out of items. Moreover, the Dyslexia Association of Ireland (2020) recognises Irish as being more transparent than English due to their orthographies and recommends that children with dyslexia opt for more transparent languages when choosing additional languages to learn.

There would appear to be some evidence, therefore, to suggest that children with SEN generally, and those with dyslexia specifically, may benefit from LIE programmes. 
Despite this, The Dyslexia Association of Ireland (2020) states that children with severe dyslexia will struggle in language learning and therefore may need to apply for an exemption from the study of compulsory Irish within mainstream schools. At the time of this study exemptions from the study of Irish were considered for children who achieved below their intellectual ability due to having a specific learning disability (DES, 1996). This policy has since been updated allowing for the decision to grant a language exemption to be made locally by the school principal on a needs basis (DES, 2019). The updated policy advises such exemptions be granted for children who have studied abroad and those presenting with significant learning difficulties scoring at/below the 10th percentile in word reading, reading comprehension or spelling. The authors would argue this updated policy makes the perspectives of principals in relation to SEN of even greater significance. However, this policy does not apply to children learning through the medium of Irish.

\section{Principals' attitudes towards inclusion}

Attitudes of school personnel towards inclusion of children with SEN are often examined since they are deemed to contribute to the overall success of inclusive education (Avramidis \& Norwich, 2002). Many school personnel within LIE programmes in Ireland believe in the benefits of LIE for pupils with SEN (Barrett, 2016). Barrett reported positive findings from her survey research with school personnel who agreed on a number of benefits of immersion education for children with SEN including bilingualism, the ease of third language acquisition, benefits to working memory and a sense of pride in the Irish language and heritage. Nonetheless, Barrett's respondents also reported high levels of agreement with a number of difficulties facing pupils with SEN in LIE such as confusion between languages, difficulties with communication, and the difficulties associated with lack of parental support due to limited parental competency in the language of instruction (in this case, Irish). These mixed findings are in keeping with the Report of Public Consultations of Exemptions (Flynn et al., 2019) in which parents argued that the benefits of second language learning for children with SEN, particularly dyslexia, are outweighed by the burden of learning a second language and the negative effects such a burden has on wellbeing and educational attainment. Furthermore, while $60 \%$ of Barrett's respondents believed students with SEN should not transfer to English medium schools, a sizeable $33.3 \%$ of respondents replied 'unsure', pointing to some uncertainty as to the suitability of enrolment in LIE for this cohort (Barrett, 2016). 
This study focuses specifically on the exploration of principals' attitudes as they are often the first point of enquiry for parents regarding enrolment of children with SEN (FlatmanWatson, 2009). Under this premise, principals' attitudes towards inclusion can have a bearing on whether or not children with SEN will be successfully enrolled in particular schools. Due to their position of leadership, principals' attitudes may influence either positively or negatively the implementation of inclusive policy and practice in mainstream schools (Praisner, 2003) as well as resource allocation within their school (Cook et al., 1999). A study by Brenann and Mac Ruairc (2011) found a number of personal values including equality, respect, justice and fairness as fundamental principles utilised for guidance by many leaders in the management of primary schools in Ireland.

Research has generally shown positive attitudes among principals towards the principle of inclusive education for children with SEN, in particular among principals who have had positive experiences with children with SEN (Praisner, 2003). Nonetheless, they still have some reservations regarding the readiness of their school to be inclusive, the feasibility of inclusion and the overall benefits of inclusive education (Cook et al., 1999). Moreover, Praisner (2003) also reports a tendency for principals to categorise children with SEN and subsequently suggest inclusion is more appropriate for some categories than others, therefore contradicting the concept of inclusion. In practice, these reservations can result in children with SEN being refused enrolment, as was the case in Flatman-Watson's study in Ireland (2009) where 54\% of her sample of families had experienced non-enrolments for their children due to principals applying 'capping' policies in their schools (where only up to a certain number of children with SEN were accepted) or 'cherry-picking' (where children with less severe needs were granted places over those with more severe needs).

\section{Method}

This study adds to recent contributions addressing this gap in research on children with SEN in LIE (Cobb, 2015; de Courcy, 2005; Dillon, 2009; DuPaul et al., 2010). Specifically, it explores primary school principals' attitudes towards Irish LIE enrolment for children with dyslexia. This study sought to examine principal attitudes towards the suitability of Irish LIE enrolment for children with dyslexia, and whether these attitudes differ based on demographic variables. It also sought to identify if there were any 
differences in attitudes between principals working in Gaelscoileanna and those working in Scoileanna Gaeltachta.

Principals from Gaelscoileanna and Scoileanna Gaeltachta were included in the study which followed a mixed methods approach involving both qualitative (focus group interviews) and quantitative (questionnaires) research methods. This design allows for the simultaneous use of multiple lenses, the triangulation of data and the enrichment of the researcher's ability to draw conclusions (Mertens, 2015).

Snowball sampling (Mertens, 2015) was used in order to recruit four principals for a focus group interview, one for the piloting of the interview questions and three for the final interview. The focus group interview was semi-structured in nature and designed to determine principals' views on the suitability, benefits and challenges of LIE enrolment for children with dyslexia. While a number of structured questions on suitability of LIE for children with SEN generally and dyslexia specifically were included (including questions on challenges faced by schools in this regard), the nature of the interview was flexible so that other themes could emerge. A key function of the focus group was to collect information that could be used to develop a more informed questionnaire. Throughout the process of the pilot interview, the focus group and the pilot questionnaire further subthemes emerged to be explored in this study. These subthemes included training, withdrawal, assessment, exemption and cross-linguistic transfer. This paper concentrates on the themes of suitability of and challenges in enrolment in LIE environments. The interviews were conducted through the medium of Irish, were audiorecorded and transcribed for analysis. Extracts quoted below have been translated into English for publication. Braun and Clarke's (2006) six-stage thematic analysis was used as a systematic and transparent way of dealing with the data in a way that is both comprehendible and replicable (Guerin, 2013).

Quantitative data came from a self-completion, anonymous online questionnaire. The questionnaire comprised eight background demographic questions to gather information on the characteristics of the respondents e.g. number of years' teaching experience, if the principal worked in a Gaelscoil or a Scoil Gaeltachta, whether they had experience working in an English-medium school, and what (if any) additional qualifications they had in special educational needs. This was followed by fifteen Likert scale questions 
asking respondents to indicate their level of agreement on a five-point scale to statements about the enrolment of children with dyslexia in LIE. Four items related to principalattitudes, seven items related to challenges in implementing LIE for children with dyslexia, and four items related to the benefits of LIE enrolment for children with dyslexia. There were also four open-ended questions on the questionnaire allowing participants to elaborate on items covered in the Likert scale. Owing to the lack of available, relevant research in this field and the subsequent challenges in developing questions for the Likert scale, the focus group interview was both necessary and helpful in order to guide questionnaire design. Data collected from the questionnaires were analysed using Statistical Package for the Social Sciences (SPSS) 23 to establish simple descriptive univariate and bivariate statistics.

The questionnaire was sent out via e-mail in March 2017 to all 237 principals working in Irish LIE settings through the email addresses available on the Department of Education and Skills website. Three follow-up e-mails and one phone call for the return of questionnaires were made during this time in order to try and increase the response rate. Forty-eight principals responded to the survey, of which 41 were completed and deemed suitable for analysis, giving a response rate of $17 \%$. The 41 respondents included 33 principals from Gaelscoileanna (approximately $80 \%$ of total responses) and eight from Scoileanna Gaeltachta (approximately $20 \%$ of total responses). Principals' profiles varied with the median number of years teaching being nine, though they ranged from two years to 34 years' experience. A total of $23(57.5 \%)$ respondents had previously taught in English medium schools while all but one principal (97.5\%) had taught students with dyslexia. Five $(12.5 \%)$ respondents had qualifications in special education in the form of either a Postgraduate diploma (1) or a Certificate (4) in Special Education.

\section{Results}

The over-riding consensus of the focus group participants was that Irish LIE placement is indeed suitable for children with dyslexia. Principals emphasised the importance of considering each child's individual needs along with the child's ability to access the curriculum: 
"I think it is suitable [Irish immersion] ...from my experience, dyslexia is not the issue ... if they succeed in both languages, or if they have the same problem in both languages well then I think ... language is not the issue, there's another issue and language is not acting as a barrier of any kind" (A2. 3)

"If they are succeeding in accessing the curriculum then there is no reason why they should not be in a Gaelscoil" (A3.4)

One exception was noted by one interviewee regarding the case of a child with specific difficulties relating to language processing:

"In particularly bad cases, where you have a child coming out at the first percentile or who is very low and there is a question of changing to a special school and the likes, there's more to discuss in those cases." (A3. 4)

Findings from a series of Likert statements on the questionnaire corroborates the generally positive findings from the interviews towards the suitability of Irish LIE placement for children with SEN with $83 \%$ of respondents either strongly agreeing or agreeing with the statement. Likewise, $78 \%$ of respondents either strongly agreed or agreed that Irish LIE placement is suitable for children with dyslexia (Table 1).

\begin{tabular}{|l|l|l|l|l|l|l|l|l|l|l|l|}
\hline $\begin{array}{l}\text { Statement } \\
\text { (statements have been } \\
\text { translated from Irish into } \\
\text { English) }\end{array}$ & $\begin{array}{l}\text { Strongly } \\
\text { agree }\end{array}$ & \multicolumn{2}{|l|}{ Agree } & \multicolumn{2}{|l|}{ Undecided } & \multicolumn{2}{|l|}{ Disagree } & \multicolumn{2}{|l|}{$\begin{array}{l}\text { Strongly } \\
\text { Disagree }\end{array}$} \\
\hline $\begin{array}{l}\text { Irish immersion education } \\
\text { is suitable for children with } \\
\text { special educational needs }\end{array}$ & 11 & 27 & 23 & 56 & 5 & 12 & 2 & 5 & 0 & 0 \\
\hline $\begin{array}{l}\text { Irish immersion education } \\
\text { is suitable for children with } \\
\text { dyslexia }\end{array}$ & 13 & 32 & 19 & 46 & 6 & 15 & 3 & 7 & 0 & 0 \\
\hline $\begin{array}{l}\text { A child with dyslexia can } \\
\text { succeed as well as, or } \\
\text { better in Irish immersion } \\
\text { than if they were in an } \\
\text { English medium school. }\end{array}$ & 10 & 24 & 24 & 59 & 4 & 10 & 2 & 5 & 1 & 2 \\
\hline
\end{tabular}


Table 1: Frequency table showing numbers and valid percentages of principals' attitudes towards the statements on the suitability of Irish LIE enrolment for children with dyslexia $(n=41)$.

Another indication of support for LIE enrolment was to establish what principals thought of the need for an exemption from the compulsory study of Irish in schools for pupils with dyslexia. $37 \%$ of Principals either strongly agreed or agreed that an exemption from Irish is sometimes needed by pupils with dyslexia though the majority (41\%) either strongly disagreed or disagreed. One of the focus group participants acknowledged the potential need for exemption for the transfer to secondary level education.

"Coming up to the transfer to secondary education ... there's a chance that it will be needed then [an exemption]. (A3. 132)

While this may indicate some degree of reluctance towards LIE for children with dyslexia, it might be more to do with the compulsory nature of Irish and the added pressures of secondary schooling for children with dyslexia, rather than the principles of LIE in and of themselves.

In spite of the general positive disposition towards LIE enrolment for children with dyslexia among participants, several concerns with the current system were highlighted. Three key challenges were identified: lack of training for staff, lack of research, and attitudes towards Irish. Analysis of the data collected from the focus group interview revealed a perception of a lack of training available to primary school teachers working in Gaelscoileanna with regard to supporting children with dyslexia. All interviewees concluded the level of training was either non-existent or poor resulting in teachers' uncertainty when supporting those with dyslexia and their parents.

"I haven't seen any training in the colleges" (A2.94)

"I see it when newly qualified teachers come into the Gaelscoil... the question arises ... they don't know the answer, they're left asking 'what happens in this case? What do I say to the parent? ... What do I do?"' (A2. 90-92) 
While maintaining that Irish immersion is suitable for children with dyslexia, one focus group participant acknowledged it is not always the correct environment for some children depending on their needs.

"It's a question of confidence on behalf of the teachers, to have the confidence to say in some situations, and cases will arise, that the Gaelscoil is not the correct setting." (A3. 62-64)

Similarly, quantitative results show only $18 \%$ (7) of principals either strongly agreed or agreed that sufficient training relating to supporting children with dyslexia is available to those working in LIE schools. Emphasis was also placed by all participants on the need for training to take into account a whole-school approach:

"I think the school approach is important" (A1.2)

"We all need to take on the responsibility of supporting children with dyslexia, everyone in the school." (A3. 117)

"If the staff don't understand, if the staff don't have the right outlook and if they're not open to children with SEN then there's a problem.” (A1. 2)

In the focus group, attention was also drawn to the issue that adequate training cannot be provided to teachers due to the lack of necessary research upon which to base its content.

"They [SESS] provide training based on research and direction provided by SESS. They have no research within this area nor anything to show a significant need within the all-Irish system, therefore they cannot provide training ... Our next endeavour must be to demand such research from the NCSE.” (A1. 106)

The lack of evidence based research more generally featured in the focus groups, in particular as it impacted on the withdrawal of children from immersion education due to a diagnosis of dyslexia. Principals argued that recommendations coming from psychologists, parents and teaching staff are based solely on anecdotal evidence and 
personal opinions.

"As soon as it is found that a child has dyslexia there is an immediate recommendation that the child be removed from the system.” (A1. 2)

"You're talking about everything being evidence based now these days ... So when you go to this person or that psychologist and if you are talking about an exemption from Irish, why is that? Is it evidence based? What have you got? And they have nothing, ever!" (A3. 143)

Overall, this indicates that there may be issues with negative attitudes towards the Irish language acting as a barrier to those wishing to support children with dyslexia through Irish LIE.

"The thing is the attitude towards Irish ... that Irish is a bad language" (A1. 77-79)

"There are children with difficulties all over the world. These children are out there and the various systems can support them and I think, in Ireland we're very closed-minded to this and that we can be particularly negative towards Irish." (A1. 21)

In particular, a parent's negative experiences with the Irish language may have an impact on their decision to remove a child from an LIE setting following a diagnosis of dyslexia, especially where one may feel unequipped to support their child's needs.

"I think a lot of it has to do with the parent's own ability in Irish and the idea they have that they may not be able to support their children within the Irish immersion system and that they will need this support always ... when they get this kind of diagnosis they feel they will always have to do the work and that they're not able ... often their own experiences of learning the language have been negative" (A3. 48) 


\subsection{Comparing Principals in Gaelscoileanna and Scoileanna Gaeltachta}

Bivariate analysis on the questionnaire data was carried out to establish if there were differences across different categories of principals in how they responded to Likert statements. While there was a very small number of principals from Scoileanna Gaeltachta (8) in this study, they responded in a remarkably different pattern on some of the Likert scale statements regarding suitability of enrolment. For example, two out of the eight respondents from Scoileanna Gaeltachta disagreed with the statement that LIE was suitable for children with SEN, and six out of eight were either undecided or disagreed that children with dyslexia could succeed as well in a LIE environment as in an English-medium environment. The small numbers in the study leave it difficult to draw conclusions about this finding, but certainly point to the need for further research in the potential for differences in perceptions between Gaelscoileanna and Scoileanna Gaeltachta principals.

Likewise, there was an observable difference in the pattern of response on exemptions from Irish among those who had prior experience of working in an English-speaking school versus those who had not (Figure 1). A Mann-Whitney U test was used to investigate if this difference was statistically significant. Results show those with previous experience working in English medium schools are more likely to agree that sometimes exemptions are necessary and this finding was statistically significant $(\mathrm{U}=$ 127.500; $\mathrm{Z}=-2.154, \mathrm{p}=0.031)$. 


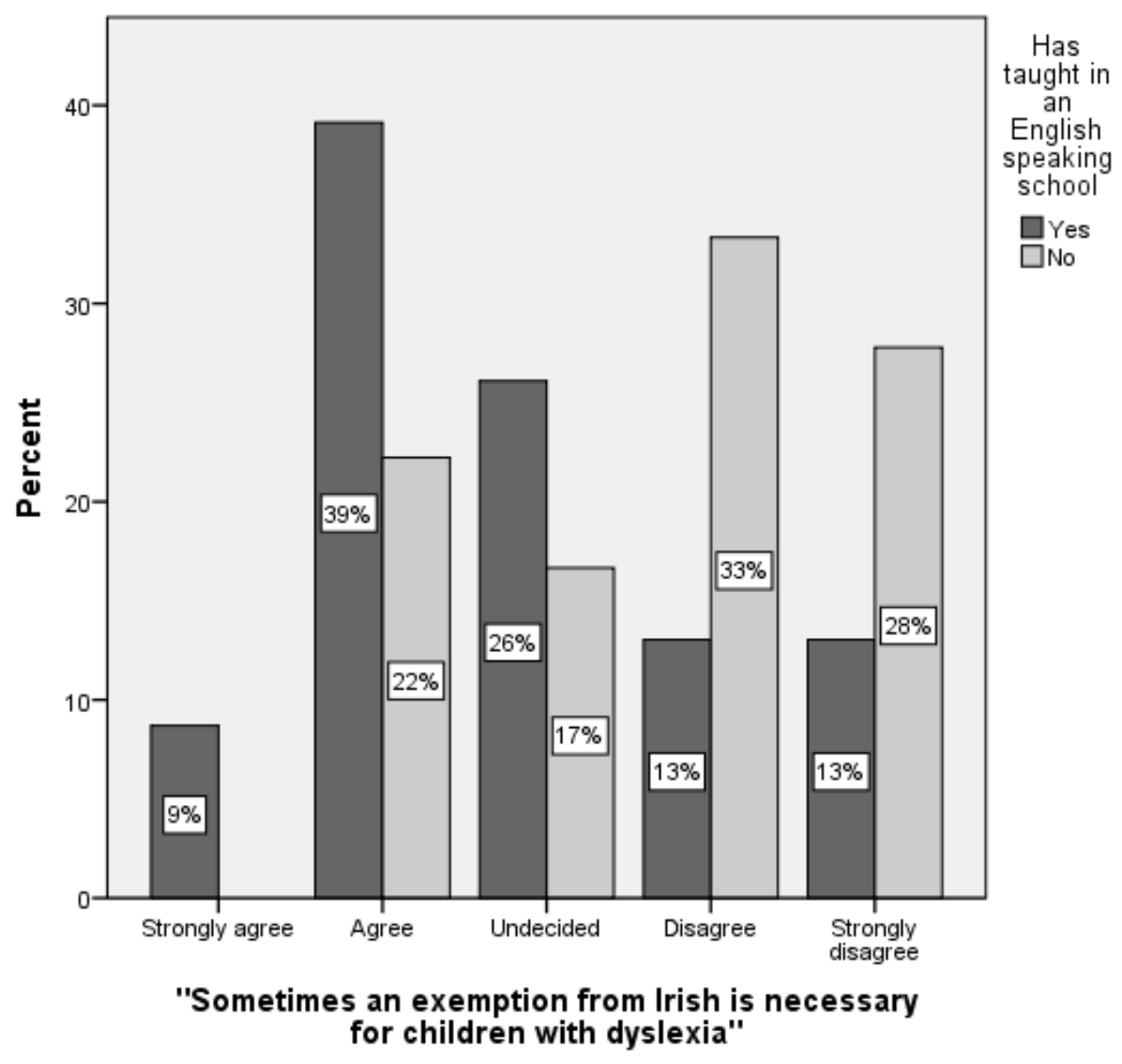

Figure 1: Graph showing principals' responses to the following statement "Sometimes an exemption from Irish is necessary for children with dyslexia"

\section{Limitations}

The low response rate on the questionnaire indicates that findings may not be generalised to the research population. In particular, the study may be particularly vulnerable to selfselection bias (Olsen, 2011) and principals with less positive attitudes towards enrolment of children with dyslexia in LIE may be disinclined to respond to a study of this nature. As such, the results below should be read with caution and future studies should endeavour, if at all possible, to obtain a smaller but random sample of LIE programmes to check the generalisability of these findings. Furthermore, it should be noted that there was no distinction made between pupils who were native Irish speakers and those acquiring Irish as a second language in the questionnaire. Subsequently, principalattitudes may be more nuanced should such a distinction be made, and should be considered in further studies. 


\section{Conclusion}

\subsection{Suitability of Irish LIE for Children with Dyslexia}

Following the data analysis of the present study it was found that while some challenges exist within the Irish LIE system making enrolment difficult for children with dyslexia, principals believe Irish LIE enrolment is suitable for children with dyslexia and SEN, that immersion education does not act as a barrier for children with dyslexia accessing the curriculum and that children with dyslexia can benefit from being educated in Scoileanna Gaeltachta and Gaelscoileanna.

The positive attitudes displayed towards immersion education for children with SEN identified in this study are in keeping with findings by Bruck (1978) and Myers (2011). However, children with needs relating specifically to language impairment and difficulty with language processing were acknowledged by focus group participants as perhaps being unsuitable for immersion education in keeping with findings by Gaffney (1999) who argued that immersion education may not be appropriate for "cognitively and linguistically immature" students. It is noteworthy that results of this study and that of Gaffney's research emphasise the necessity of looking at the particular needs of each child individually in order to make decisions in conjunction with the parents, which is in keeping with the updated policy regarding exemption from Irish (DES, 2019).

Results of the current study show principals' attitudes are mixed in relation to exemptions from Irish. These contradictory findings may be due to the influence of professionals, blogs and internet forums suggesting that children with SEN would be 'better off' learning only one language (Ware, 2011). Similarly, the Dyslexia Association of Ireland (2020) suggest exemption for those diagnosed with severe dyslexia. However, as highlighted by the findings of this study, such suggestions are not evidence based and no literature could be found in support of them.

Results of this study identified and consolidated previously identified challenges faced by children with SEN and those who support them in Irish medium schools. Challenges include shortcomings of the current assessment facilities available to those within Irish LIE programmes (Murphy \& Travers, 2012; O’Toole \& Hickey, 2012) along with a lack of training (Barrett, 2016; Mac Donnacha, 2005) and research (Ní Chiaruáin, 2009) to help guide those working within the system. In the years succeeding this study a Policy 
on Gaeltacht Education (2017) has been produced in order to provide the necessary supports to ensure the delivery of a high-quality education to those learning in scoileanna Gaeltachta. Moreover the Report of Public Consultations of Exemptions (Flynn et al., 2019) addresses these same challenges noting an issue of misinformation amongst clinical and teaching staff and calling for better training regarding the cognitive benefits of bilingualism for children with SEN as well as the implementation of an inclusive and differentiated approach to language learning for all students.

Differences were identified between attitudes of principals working in Gaelscoileanna and Scoileanna Gaeltachta towards the suitability of LIE for children with SEN, though given the small numbers in the latter group, further research is needed to explore this finding. These findings are somewhat contradictory of findings by Barrett (2016) who reported a greater tendency of transfer of children with SEN to English immersion schools in Gaelscoileanna than in Scoileanna Gaeltachta, though this may because of the availability of local enrolment alternatives in the former, but not the latter. While there were no differences found statistically, the current study shows a tendency for principals working in Scoileanna Gaeltachta to be more in favour of children with dyslexia having exemptions from Irish than principals working in Gaelscoileanna. In keeping with this, pupils in Gaelscoileanna have been reported to have more positive attitudes towards Irish than pupils in Scoileanna Gaeltachta (Darmody \& Daly, 2015).

The present study explores principals' attitudes towards the suitability of Gaelscoil enrolment for children with dyslexia strengthening the evidence-base existing surrounding SEN and immersion education. Furthermore, this study has identified challenges faced by children with dyslexia in Gaelscoileanna as well as those supporting them. Nonetheless, the study is based on a small participant pool and the low response rate means the findings may not be generalizable. Furthermore, there is an imbalance in the number of respondents working in Gaelscoileanna and Scoileanna Gaeltachta. Future studies should endeavour to have a larger, more balanced sample. 


\section{References}

An Comhairle um Oideachas Gaeltachta agus Gaelscolaíochta. (COGG) (2010). Riachtanais speisialta oideachas i scoileanna ina bhfuil an ghaeilge mar mhean: Taighde uile-oileánda ar riachtanais tacaíochta agus traenála na hearnála. An Comhairle um Oideachas Gaeltachta agus Gaelscolaiochta: POBAL.

Baker, C. (2000). The care and education of young bilinguals: An introduction for professionals. Clevedon: Multilingual Matters.

Baker, C. (2011). Foundations of bilingual education and bilingualism (Vol. 79). Clevedon: Multilingual Matters.

Barrett, M. (2016). Doras Feasa Fiafraí: Exploring Special Educational Needs Provision and Practices across Gaelscoileanna and Gaeltacht Primary Schools in the Republic of Ireland. Retrieved February, 19, 2017 from http://www.cogg.ie/wpcontent/uploads/doras-feas-fiafrai.pdf

Braun, V., \& Clarke, V. (2006). Using thematic analysis in psychology. Qualitative Research in Psychology, 3(2), 77-101.

Brennan, J., \& Mac Ruairc, G. (2011). Taking it personally: examining patterns of emotional practice in leading primary schools in the Republic of Ireland. International Journal of Leadership in Education, 14(2), 129-150.

British Dyslexia Association. (2017). Dyslexia style guide. Retrieved 14 ${ }^{\text {th }}$ May 2017. Available from: http://www.bdadyslexia.org.uk/common/ckeditor/filemanager/ userfiles/About_Us/policies/Dyslexia_Style_Guide.pdf

Bruck, M. (1978). The suitability of early French immersion programmes for the language-disabled child. Canadian Journal of Education, 3(4), 51-72.

Central Statistics Office (2017). Census of Population 2016: Profile 10 Education, Skills and the Irish Language. Online at http://www.cso.ie/en/releasesandpublications/ep/p-cp10esil/p10esil/:

Cline, T. (2000). Multilingualism and dyslexia: Challenges for research and practice. Dyslexia, 6(1), 3-12.

Cohen, L., Manion, L., \& Morrison, K. (2011). Research methods in education (7th ed.). London: Routledge.

Cook, B. G., Semmel, M. I., \& Gerber, M. M. (1999). Attitudes of principals and special education teachers toward the inclusion of students with mild disabilities: Critical differences of opinion. Journal for Special Educators, 20(4), 199-207. 
Cummins, J. (2005). Teaching for cross-language transfer in dual language education: Possibilities and pitfalls. In TESOL Symposium on dual language education: Teaching and learning two languages in the EFL setting, pp. 1-18.

Cummins, J. (1983). Bilingualism and special education: Programme and pedagogical issues. Learning Disability Quarterly, 6(4), 373-386

Darmody, M., \& Daly, T. (2015). Attitudes towards the Irish language on the island of Ireland. Dublin: ESRI.

Department of Education and Science. (1999). Primary School Curriculum Introduction. Dublin: Author.

Department of Education and Science. (1996). Revision of circular 18/79: Exemption from the study of Irish. Dublin: Author.

Department of Education and Skills. (2017). "Data on Individual Schools." Department of Education and Skills.

Department of Education and Skills. (2017). Policy on Gaeltacht Education 2017-2022. Gaeltacht School Rocognition Scheme for Primary School and Special Schools in Gaeltacht Language-Planning Areas. Initial Implementation Phase (April 2017 to June 2018). Dublin: Author.

Department of Education and Skills. (2019). Exemptions from the study of Irish revising circular 12/96. Dublin: Author.

Dillon, A. M. (2009). Metalinguistic awareness and evidence of cross-linguistic influence among bilingual learners in Irish primary schools. Language Awareness, 18(2), $182-197$

Dyslexia Association of Ireland. (2020). Language learning. Retrieved 17 th July 2020. Available from: $\quad$ http://www.dyslexia.ie/information/information-forstudents/language-learning/

Everatt, J., Weeks, S., \& Brooks, P. (2008). Profiles of strengths and weaknesses in dyslexia and other learning difficulties. Dyslexia, 14(1), 16-41.

Flatman-Watson, S. (2009). Barriers to inclusive education in Ireland: The case for pupils with a diagnosis of intellectual and/or pervasive developmental disabilities. British journal of learning disabilities, 37(4), 277-284.

Flynn, N., Murray, C., Lynch, A. and Davitt, E. (2019). Report on public consultation on exemptions from the study of Irish in schools. Galway: National University of Ireland, Galway. 
Gaelscoileanna Teo. (2016). Statisitcs. Retrieved $7^{\text {th }}$ December 2016. Available from: http://www.gaelscoileanna.ie/en/about/statistics/

Gaffney, K. S. (1999). Is immersion education appropriate for all students? ACIE Newsletter, 2(2).

Genesee, F. (2007). French immersion and at-risk students: A review of research evidence. Canadian Modern Language Review, 63(5), 655-687.

Genesee, F., \& Jared, D. (2008). Literacy development in early French immersion programmes. Canadian Psychology/Psychologie canadienne, 49(2), 140.

Government of Ireland. (1998).The education act. Dublin: The Stationery Qffice.

Government of Ireland. (2004). Education for persons with special educational needs act. Dublin: The Stationary Office.

Gwernan-Jones, R., \& Burden, R. L. (2010). Are they just lazy? Student teachers' attitudes about dyslexia. Dyslexia, 16(1), 66-86.

Hickey, T. (2001). Reading in a second language: Teaching Irish reading. Nóta ón Eagarthóir, 7(2), 66.

Hickey, T. M. (2007). Fluency in reading Irish as L1 or L2: Promoting high-frequency word recognition in emergent readers. International Journal of Bilingual Education and Bilingualism, 10(4), 471-493.

Hickey, T. M., \& Stenson, N. (2016). One step forward and two steps back in teaching an endangered language? Revisiting L2 reading in Irish. Language, Culture and Curriculum, 29(3), 302-318.

International Dyslexia Association. (2016). Definition of Dyslexia. Retrieved $26^{\text {th }}$ November 2016. Available from https://dyslexiaida.org/definition-of-dyslexia/

Joshi, R. M., Padakannaya, P., \& Nishanimath, S. (2010). Dyslexia and hyperlexia in bilinguals. Dyslexia (Chichester, England), 16(2), 99-118.

Mac Donnacha, S. (2005). Staid Reatha na Scoileanna Gaeltachta/ A Study of Gaeltacht Schools 2004. Dublin: An Chomhairle um Oideachas Gaeltachta \& Gaelscolaíochta.

McPhillips, T., Bell, S., \& Doveston, M. (2009). Indentification and intervention for primary pupils with dyslexia in Ireland and England: Finding a path through the maze. REACH Journal of Special Needs Education in Ireland, 22(2), 67-81.

Mertens, D. M. (2015). Research and evaluation in education and psychology: Integrating diversity with quantitative, qualitative, and mixed methods (4th ed.). London: Sage publications. 
Miles, M.B., \& Huberman, A.M. (1994). Qualitative data analysis: An expanded sourcebook. London: Sage.

Miller-Guron, L., \& Lundberg, I. (2000). Dyslexia and second language reading: A second bite at the apple? Reading and Writing, 12(1), 41-61.

Murphy, D., \& Travers, J. (2012). Including young bilingual learners in the assessment process: A study of appropriate early literacy assessments utilising both languages of children in a Gaelscoil. In T. Day \& J. Travers (Eds.), Special and inclusive education: A research perspective, pp. 167-184. Oxford: Peter Lang.

Myers, M. L. (2011). Achievement of children identified with special needs in two-way Spanish immersion programmes. ACIE Newsletter - The Bridge April: 1-8.

Ní Chiaruáin, M. (2009). An examination of how children with dyslexia experience reading in two languages in a Gaelscoil. Unpublished MSEN thesis, St. Patrick's College, Drumcondra, Dublin.

Nulty, D. D. (2008). The adequacy of response rates to online and paper surveys: What can be done? Assessment \& Evaluation in Higher Education, 33(3), 301-314.

Ó'Murchú, Helen. (2001). Irish: The Irish Language in Education in the Republic of Ireland. Online at http://www1.fa.knaw.nl/mercator/regionale _dossiers/PDFs/irish_in_ireland.pdf: European Research Centre on Multilingualism and Language Learning.

O’Toole, C., \& Hickey, T. M. (2012). Diagnosing language impairment in bilinguals: Professional experience and perception. Child Language Teaching and Therapy, 29(1), 91-109.

Olsen, R. (2011). "Self-selection bias”. In Lavrakas, P. (2011) Encyclopedia of Survey Research Methods. Thousand Oaks, CA: Sage Publications. Online at http://dx.doi.org/10.4135/9781412963947

Parsons, C., E., \& Lyddy, F. (2009). Early reading strategies in Irish and English: Evidence from error types. Reading in a Foreign Language, 21(1), 22-36.

Parsons, C., \& Lyddy, F. (2015). A longitudinal study of early reading development in two languages: comparing literacy outcomes in Irish immersion, English medium and Gaeltacht schools. International Journal of Bilingual Education and Bilingualism, 1-19.

Peterson, R. L., \& Pennington, B. F. (2012). Developmental dyslexia. Lancet (London, England), 379(9830), 19-97. 
Praisner, C. L. (2003). Attitudes of elementary school principals toward the inclusion of students with disabilities. Exceptional children, 69(2), 135-145.

Reid, G. (2016). Dyslexia: A practitioner's handbook (5th ed.). John Wiley \& Sons.

Reid, G. (2004) Dyslexia. In Lewis, A., \& B. Norwich (Eds.), Special teaching for special children? Pedagogies for inclusion, pp. 138-149. Maidenhead: McGraw-Hill Education (UK).

Robson, C. (2002). Real world research: A resource for users of social research methods in applied settings ( $\left.2^{\text {nd }} e d.\right)$. West Sussex: John Wiley.

Rhys, M., \& Thomas, E. (2012). Bilingual Welsh-English children's acquisition of vocabulary and reading: implications for bilingual education. International Journal of Bilingual Education and Bilingualism, 16(6), 633-656.

Ware, J. (2011) Squaring the circle: Supporting bilingual children with SEN - what do we know, and what do we need to know? Keynote presentation at the launch of the report into the special needs of bilingual children in Ireland Dublin.

Ware, J., Lye, C. B., \& Kyffin, F. (2015). Bilingualism and Students (Learners) With Intellectual Disability: A Review. Journal of Policy and Practice in Intellectual Disabilities, 12(3), 220-231.

Wydell, T. N., \& Butterworth, B. (1999). A case study of an English-Japanese bilingual with monolingual dyslexia. Cognition, 70(3), 273-305. 